\title{
Liquid crystalline polymers IX Main chain thermotropic poly (azomethine - ether)s containing thiazole moiety linked with polymethylene spacers
}

\author{
K. I. Aly*, M. A. Abbady, S. A. Mahgoub, M. A. Hussein \\ Polymer Laboratory 122, Chemistry Department, Faculty of Science, Assiut University, Assiut, 71516, Egypt
}

Received 3 December 2006; accepted in revised form 18 March 2007

\begin{abstract}
A new homologous series of thermally stable thermotropic liquid crystalline poly(azomethine-ether)s based on thiazole moiety were synthesized by solution polycondensation of 4,4'-diformyl- $\alpha, \omega$-diphenoxyalkanes, I-IV or 4,4 ' diformyl-2,2'-dimethoxy- $\alpha, \omega$,-diphenoxyalkanes V-VIII with the new bis(2-aminothiazole) monomer X. A model compound $\mathbf{X I}$ was synthesized from $\mathbf{X}$ with benzaldehyde and characterized by elemental and spectral analyses. The inherent viscosities of the resulting polymers were in the range $0.43-1.34 \mathrm{dl} / \mathrm{g}$. All the poly(azomethine-ether)s were insoluble in common organic solvents but dissolved completely in concentrated $\mathrm{H}_{2} \mathrm{SO}_{4}$ and formic acid. The mesomorphic properties of these polymers were studied as a function of the diphenoxyalkane space length. Their thermotropic liquid crystalline properties were examined by DSC and optical polarizing microscopy and demonstrated that the resulting polymers form nematic mesophases over wide temperature ranges. The thermogravimetric analyses of those polymers were evaluated by TGA and DSC measurements and correlated to their structural units. X-ray analysis showed that polymers having some degree of crystallinity in the region $2 \theta=5-60^{\circ}$. In addition, the morphological properties of selected examples were tested by scanning electron microscopy.
\end{abstract}

Keywords: polymer synthesis, molecular engineering, liquid crystal, thermotropic, thermal properties, thiazole poly(azomethine-ether)s

\section{Introduction}

Polymers incorporating mesogenic moieties in the main chain are known to exhibit liquid crystalline behavior. The direct study of mesomorphic homopolymers is however frequently hampered by their high melting points. Lowering of the solid crystal to liquid crystal transition temperature may be effected by separation of the rigid mesogenic moieties with regularly spaced sequences of flexiblizing groups or by co-polycondensation [1, 2]. However, most wholly aromatic poly(azomethine)s have high softening temperatures which make melt spinning and injection molding impracticable [3, 4]. These polymers may start to decompose before

*Corresponding author, e-mail: Kamal_61@yahoo.com

(C) BME-PT and GTE reaching the melting point. One method for lowering the high melting point of rod-like polymers is to introduce flexible aliphatic units into the main chain [5]. This lowering may be also achieved by using substituent group, thereby increasing the diameter or decreasing the axial ratio of the mesogenic units [6]. Thermotropic (heat-induced) liquid crystalline behavior of polymeric materials is of considerable current interest, not only because of their potential as high-strength fibers, plastics, moldings, etc [7]. Morgan et al. [8] described the preparation and properties of a variety of wholly aromatic melt-anisotropic poly(azomethine)s. However, a literature survey revealed that few poly(azomethine)s had been synthesized $[9,10]$. 
The first poly(azomethine)s were prepared by Guillon and Skoulios [9] from benzidine and 4,4'diformyl- $\alpha, \omega$-diphenoxydecane. Also, terephthaldehyde was reacted with 4,4'-diamino- $\alpha, \omega$ diphenoxyalkanes to obtain poly(azomethineether)s [10]. Li and Chang [11] synthesized a series of poly(azomethine-ether)s by the condensation of 1,4-phenylenediamine and 4,4'-diformyl- $\alpha, \omega$-diphenoxyalkane derivatives and studied their LC properties. On the other hand, the anisotropy of the liquid crystalline mesophase offers the possibility of production of novel high performance materials, exhibiting excellent properties due to a proper arrangement of macromolecules in the mesophase during the processing. Moreover, polymers exhibiting liquid crystallinity consist of macromolecules with rigid structure, characterized by high extension of backbones. A major aim of this work has been to investigate the effect of inclusion of flexible spacers as well as thiazole moiety on the liquid crystal properties. In addition, other characteristics of these polymers such as thermostability, solubility, morphology and crystallinity are discussed.

\section{Experimental}

\subsection{Measurements}

Elemental analyses were carried out using an Elemental Analyses system GmbH, VARIOEL, $V_{2.3}$ July 1998 CHNS Mode. Infrared Spectra from $4000-600 \mathrm{~cm}^{-1}$ of solid samples of the synthesized monomers and polymers were obtained by the $\mathrm{KBr}$ method using a Shimadzu 2110 PC Scanning Spectrophotometer. The ${ }^{1} \mathrm{H}-\mathrm{NMR}$ spectra were recorded on a GNM-LA 400-MHz NMR spectrophotometer at room temperature in DMSO or $\mathrm{CDCl}_{3}$ using TMS as the internal reference. Mass spectra were recorded on a Jeol JMS 600 mass spectrometer. The inherent viscosity was measured with an Ubbelhode Viscometer in Conc. $\mathrm{H}_{2} \mathrm{SO}_{4}$ at $30^{\circ} \mathrm{C}$ $(0.5 \mathrm{~g} / \mathrm{l})$. The solubility of polymers were examined using $0.02 \mathrm{~g}$ of polymer in $3-5 \mathrm{ml}$ of solvent at room temperature. The X-ray diffractographs of the polymers were obtained with a Philips X-ray pw 1710 diffractometer, and $\mathrm{Ni}$-filtered $\mathrm{CuK}_{\alpha}$ radiations. Thermogravimetric analysis (TGA) and differential thermogravmetry (DTG) were carried out in air with TA 2000 thermal analyzer at heating rate of $10^{\circ} \mathrm{C} / \mathrm{min}$ in air. The maximum position of the melting endotherms was taken to be the m.p.s. The isotropization temperatures were determined by observing polymer melts with a polarizing microscope, GARL-ZEISS (JENA) equipped with a hotstage Chaixmeca (Nancy, France). The temperature at which initial formation of isotropic phases occurred was taken as the isotropization temperature, $T_{i}$. At the same time, optical textures of the polymer melts were very closely followed to determine the nature of their mesophase. The morphologies of polymers were examined by scanning electron microscopy (SEM) using a Jeol JSM-5400 LV instrument.

\subsection{Reagents and solvents}

Diphenylether from (Merck) was used without purification. p-hydroxy-benzaldehyde from (Aldrich) was used without crystallization. 4-hydroxy-3methoxybenzaldehyde (vanillin) from EL-Nassr Chemical Company (Egypt) was used as it is. Dihaloalkanes (Aldrich) were used without purification. All solvents and other reagents were of high purity and were further purified by standard methods [12].

\subsection{Monomers syntheses}

\subsubsection{Synthesis of 4,4'-bis(2"'-aminothiazol- 4"-yl)diphenyl ether $\mathrm{X}$}

A mixture of $1 \mathrm{gm}\left(3.09 \cdot 10^{-3}\right.$ mole $)$ of $4,4^{\prime}$ bis(chloroacetyl)diphenyl ether IX; and $0.47 \mathrm{gm}$ $\left(6.18 \cdot 10^{-3} \mathrm{~mole}\right)$ of thiourea in $20 \mathrm{ml}$ absolute ethanol was refluxed for 4 hours. The clear solution was poured onto cold sodium acetate solution and the precipitated product was collected by filtration and crystallized from ethyl acetate as yellowish crystals, m.p $240^{\circ} \mathrm{C}$, and yield $87 \%$.

Anal. Calc. for $\mathrm{C}_{18} \mathrm{H}_{14} \mathrm{~N}_{4} \mathrm{OS}_{2}$ :

C, 59.01; H, 3.82; N, 15.30; S, 17.48 .

Found: C, 58.95; H, 3.86; N, 15.13; S, 17.59.

\subsubsection{Preparation of $\mathbf{4 , 4}$ '-diformyl- $\alpha, \omega$ - diphenoxyalkanes I-IV and \\ 4,4'-diformyl-2,2'dimethoxy- $\alpha, \omega$ - diphenoxyalkanes V-VIII}

The title compounds were prepared as described previously in the literature [13], and also as described in our previous papers $[14,15]$. 


\subsection{Synthesis of model compound - (2"-methylideneamino-thiazol-4"-yl)- diphenyl ether XI}

Model compound was synthesized by refluxing a mixture of monomer $\mathbf{X}\left(2.73 \cdot 10^{-3}\right.$ mole $)$ and benzaldehyde $\left(4.6 \cdot 10^{-3}\right.$ mole) in about $20-25 \mathrm{ml}$ of absolute ethanol in the presence of few drops of piperidine as a catalyst for 6 hours. The precipitated product was collected by filtration as yellow crystals and recrystallized from ethanol, m.p $158^{\circ} \mathrm{C}$, and yield $85 \%$.

Anal. Calc. for $\mathrm{C}_{32} \mathrm{H}_{22} \mathrm{~N}_{4} \mathrm{OS}_{2}$ :

$$
\text { C, 70.84; H, 4.05; N, 10.33; S, } 11.80 \text {. }
$$

Found: C, 70.90; H, 3.98; N, 10.39; S, 11.76 .

\subsection{Polymerization}

\section{General procedures}

A typical example of the polycondensation for poly (azomethine-ether)s $\mathbf{X I I}_{\mathbf{a}-\mathbf{e}}$ and $\mathbf{X I I I}_{\mathbf{a}-\mathbf{e}}$ is now described:

In a three necked flask equipped with a condenser, dry nitrogen inlet, outlet, and dropping funnel, a mixture of $\left(2 \cdot 10^{-3}\right.$ mole $)$ bis(2-aminothiazole) monomer $\mathbf{X}$ suspended in $20-30 \mathrm{ml}$ absolute ethanol and a few drops of piperidine was introduced as a basic catalyst. The different prepared bis-aldehydes $\left(2 \cdot 10^{-3}\right.$ mole) was dissolved in $15 \mathrm{ml}$ of absolute ethanol was added in dropwise manner at $25^{\circ} \mathrm{C}$, during the stirring in about 20 minutes. After complete the addition of bis-aldehydes, the stirring was continued for $12-15 \mathrm{hrs}$. at $\sim 80^{\circ} \mathrm{C}$, during this time, the viscosity of the solution increased rapidly and the polymer began to precipitate in the early stages of the reaction. The polymer precipitated was isolated by filtration as a highly yellowish solid polymers, then washed with hot methanol and hot acetone and then dried under reduced pressure $(1 \mathrm{~mm} / \mathrm{Hg})$ at $80^{\circ} \mathrm{C}$ for 48 hours.

All the poly(azomethine-ether)s were synthesized by an analogous procedure. Their yields, inherent viscosities, and elemental analyses are listed in Table 1.

\section{Results and discussion}

\subsection{Monomer synthesis}

A new series of thermotropic liquid crystalline poly(azomethine-ether)s based on thiazole moiety were synthesized. The monomer compound $\mathbf{X}$ was synthesized by the interaction of 4,4'-bis(chloroacetyl)diphenyl ether IX with thiourea in absolute ethanol, most probably according to the following known mechanism [16], which is based on the interaction of enol form of the diketone with the mercapto form of thiourea through elimination of $\mathrm{H}_{2} \mathrm{O}$ and $\mathrm{HCl}$ molecules from the reactants, as shown in Figure 1.

Table 1. Elemental analyses, yields and inherent viscosity of poly(azomethine-ether)s $\mathbf{X I I}_{\mathbf{a}-\mathbf{e}}$ and $\mathbf{X I I I}_{\mathbf{a}-\mathbf{e}}$

\begin{tabular}{|c|c|c|c|c|c|c|c|c|}
\hline \multirow{2}{*}{$\begin{array}{l}\text { Polymer } \\
\text { number }\end{array}$} & \multirow{2}{*}{$\begin{array}{l}\text { Yield } \\
{[\%]}\end{array}$} & \multirow{2}{*}{$\begin{array}{c}\eta^{*} \text { inh } \\
{[d I / g]}\end{array}$} & \multirow{2}{*}{$\begin{array}{c}\text { Molecular formula } \\
{[\mathrm{mol} . \mathrm{Wt} .]}\end{array}$} & \multicolumn{5}{|c|}{ Elemental analyses } \\
\hline & & & & & $\mathrm{C}[\%]$ & $\mathbf{H}[\%]$ & $\mathbf{N}[\%]$ & $\mathbf{S}[\%]$ \\
\hline $\mathbf{X I I}_{\mathbf{a}}$ & 72 & 0.61 & $\begin{array}{c}\mathrm{C}_{34} \mathrm{H}_{24} \mathrm{~N}_{4} \mathrm{O}_{3} \mathrm{~S}_{2} \\
(600)\end{array}$ & $\begin{array}{l}\text { Calcd } \\
\text { Found }\end{array}$ & $\begin{array}{l}68.00 \\
67.22\end{array}$ & $\begin{array}{l}4.00 \\
3.66\end{array}$ & $\begin{array}{l}9.33 \\
9.56\end{array}$ & $\begin{array}{l}10.66 \\
10.22\end{array}$ \\
\hline b & 87 & 0.49 & $\begin{array}{c}\mathrm{C}_{36} \mathrm{H}_{28} \mathrm{~N}_{4} \mathrm{O}_{3} \mathrm{~S}_{2} \\
(628)\end{array}$ & $\begin{array}{l}\text { Calcd } \\
\text { Found }\end{array}$ & $\begin{array}{l}68.78 \\
67.83\end{array}$ & $\begin{array}{l}4.45 \\
4.70\end{array}$ & $\begin{array}{l}8.91 \\
8.60\end{array}$ & $\begin{array}{c}10.19 \\
9.92\end{array}$ \\
\hline c & 91 & 0.53 & $\begin{array}{c}\mathrm{C}_{38} \mathrm{H}_{32} \mathrm{~N}_{4} \mathrm{O}_{3} \mathrm{~S}_{2} \\
(656)\end{array}$ & $\begin{array}{l}\text { Calcd } \\
\text { Found }\end{array}$ & $\begin{array}{l}69.51 \\
68.08\end{array}$ & $\begin{array}{l}4.87 \\
4.34\end{array}$ & $\begin{array}{l}8.53 \\
8.19\end{array}$ & $\begin{array}{l}9.75 \\
9.29\end{array}$ \\
\hline d & 75 & 0.95 & $\begin{array}{c}\mathrm{C}_{40} \mathrm{H}_{36} \mathrm{~N}_{4} \mathrm{O}_{3} \mathrm{~S}_{2} \\
(684)\end{array}$ & $\begin{array}{l}\text { Calcd } \\
\text { Found }\end{array}$ & $\begin{array}{l}70.17 \\
68.99\end{array}$ & $\begin{array}{l}5.26 \\
4.88\end{array}$ & $\begin{array}{l}8.18 \\
7.89\end{array}$ & $\begin{array}{l}9.35 \\
9.55\end{array}$ \\
\hline e & 85 & 0.85 & $\begin{array}{c}\mathrm{C}_{42} \mathrm{H}_{40} \mathrm{~N}_{4} \mathrm{O}_{3} \mathrm{~S}_{2} \\
(712)\end{array}$ & $\begin{array}{l}\text { Calcd } \\
\text { Found }\end{array}$ & $\begin{array}{l}70.78 \\
69.77\end{array}$ & $\begin{array}{l}5.61 \\
5.28\end{array}$ & $\begin{array}{l}7.86 \\
7.38\end{array}$ & $\begin{array}{l}8.98 \\
8.61\end{array}$ \\
\hline $\mathbf{X I I I}_{\mathrm{a}}$ & 79 & 0.81 & $\begin{array}{c}\mathrm{C}_{36} \mathrm{H}_{28} \mathrm{~N}_{4} \mathrm{O}_{5} \mathrm{~S}_{2} \\
(660)\end{array}$ & $\begin{array}{l}\text { Calcd } \\
\text { Found }\end{array}$ & $\begin{array}{l}65.45 \\
63.88\end{array}$ & $\begin{array}{l}4.24 \\
3.94\end{array}$ & $\begin{array}{l}8.48 \\
8.40\end{array}$ & $\begin{array}{l}9.69 \\
9.55\end{array}$ \\
\hline b & 84 & 0.65 & $\begin{array}{c}\mathrm{C}_{38} \mathrm{H}_{32} \mathrm{~N}_{4} \mathrm{O}_{5} \mathrm{~S}_{2} \\
(688)\end{array}$ & $\begin{array}{l}\text { Calcd } \\
\text { Found }\end{array}$ & $\begin{array}{l}66.27 \\
65.09\end{array}$ & $\begin{array}{l}4.65 \\
4.92\end{array}$ & $\begin{array}{l}8.13 \\
7.96\end{array}$ & $\begin{array}{l}9.30 \\
9.22\end{array}$ \\
\hline c & 93 & 1.21 & $\begin{array}{c}\mathrm{C}_{40} \mathrm{H}_{36} \mathrm{~N}_{4} \mathrm{O}_{5} \mathrm{~S}_{2} \\
(716)\end{array}$ & $\begin{array}{l}\text { Calcd } \\
\text { Found }\end{array}$ & $\begin{array}{l}67.03 \\
65.79\end{array}$ & $\begin{array}{l}5.02 \\
4.67\end{array}$ & $\begin{array}{l}7.82 \\
7.66\end{array}$ & $\begin{array}{l}8.93 \\
9.04\end{array}$ \\
\hline d & 78 & 0.79 & $\begin{array}{c}\mathrm{C}_{42} \mathrm{H}_{40} \mathrm{~N}_{4} \mathrm{O}_{5} \mathrm{~S}_{2} \\
(744)\end{array}$ & $\begin{array}{l}\text { Calcd } \\
\text { Found }\end{array}$ & $\begin{array}{l}67.74 \\
66.33\end{array}$ & $\begin{array}{l}5.37 \\
4.97\end{array}$ & $\begin{array}{l}7.52 \\
7.17\end{array}$ & $\begin{array}{l}8.60 \\
8.43\end{array}$ \\
\hline e & 90 & 1.19 & $\begin{array}{c}\mathrm{C}_{44} \mathrm{H}_{44} \mathrm{~N}_{4} \mathrm{O}_{5} \mathrm{~S}_{2} \\
(772)\end{array}$ & $\begin{array}{l}\text { Calcd } \\
\text { Found }\end{array}$ & $\begin{array}{l}68.39 \\
67.46\end{array}$ & $\begin{array}{l}5.69 \\
5.11\end{array}$ & $\begin{array}{l}7.25 \\
7.55\end{array}$ & $\begin{array}{l}8.29 \\
8.13\end{array}$ \\
\hline
\end{tabular}

*Measured in $\mathrm{H}_{2} \mathrm{SO}_{4}$, with $\mathrm{C}=0.5 \mathrm{~g} / 100 \mathrm{ml}$ at $30^{\circ} \mathrm{C}$ 

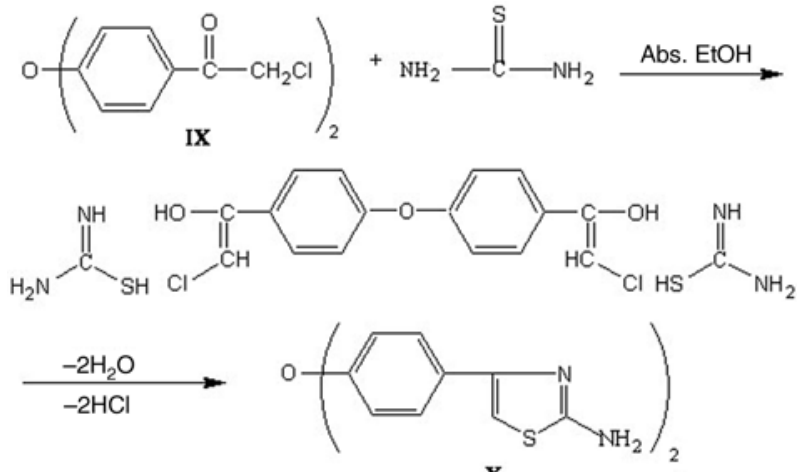

$\mathbf{x}$

Figure 1. Synthesis of monomer $\mathbf{X}$

Elucidation of the structure o monomer $\mathbf{X}$ was based on correct elemental and spectral data. The IR spectrum displayed characteristic absorption bands at $3400-3290 \mathrm{~cm}^{-1}$ due to primary amino group and absorption band at $1625 \mathrm{~cm}^{-1}$ due to $\mathrm{C}=\mathrm{N}$. The ${ }^{1} \mathrm{H}-\mathrm{NMR}$ spectrum (in DMSO- $\mathrm{d}_{6}, \mathrm{ppm}$ ) showed the following $\delta$ values: at 7.8-6.95 $(\mathrm{m}, 8 \mathrm{H}$ of aromatic and 2-CH-S) and at 6.97 (s, $4 \mathrm{H}$ of primary amino group, interfered with the aromatic protons and exchangeable with $\mathrm{D}_{2} \mathrm{O}$ ). The mass spectrum exhibited a molecular ion peak at $\mathrm{m} / \mathrm{z}=$ 365.80 (100\%) which is in agreement with its molecular formula $\left(\mathrm{C}_{18} \mathrm{H}_{14} \mathrm{~N}_{4} \mathrm{OS}_{2}\right)$. Other peaks were observed at $m / z=333.80\left(\mathrm{M}^{+}-2 \mathrm{NH}_{2}, 0.4 \%\right)$; at $m / z=267.77\left(\mathrm{M}^{+}-\mathrm{C}_{3} \mathrm{H}_{3} \mathrm{~N}_{2} \mathrm{~S}, 19.1 \%\right)$ and at $m / z=167.86\left(\mathrm{M}^{+}-\mathrm{C}_{6} \mathrm{H}_{6} \mathrm{~N}_{4} \mathrm{~S}_{2}, 0.4 \%\right)$.

\subsection{Synthesis of model compound}

Before attempting polymerization, model compound XI for the desired poly(azomethine-ether)s was synthesized by the interaction of 1 mole of monomer $\mathbf{X}$ with 2 moles of benzaldehyle in absolute ethanol ad in the presence of few drops of piperidine as a basic catalyst [17] as described in Figure 2.

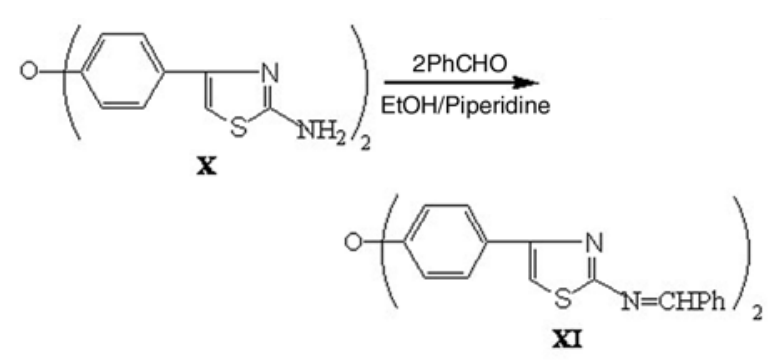

Figure 2. Synthesis of Model Compound XI

The structure of model compound XI was confirmed by both correct elemental and spectral analyses. The IR spectrum showed the disappearance of $\mathrm{NH}_{2}$ vibration at $3400-3290 \mathrm{~cm}^{-1}$ and gave characteristic absorption bands at $1596 \mathrm{~cm}^{-1}$ due to $\mathrm{C}=\mathrm{N}$. The ${ }^{1} \mathrm{H}-\mathrm{NMR}$ spectrum (in T.F.A., ppm) showed the following values: at $8.01-7.01(\mathrm{~m}, 18 \mathrm{H}$ of aromatic protons), and at $9.56(\mathrm{~s}, 2 \mathrm{H}$ oh the $-\mathrm{S}-\mathrm{CH}=$ ). While, the mass spectrum of model compound XI exhibited a molecular ion peak at $\mathrm{m} / \mathrm{z}=542(0.2 \%)$ which is in agreement with its molecular formula $\left(\mathrm{C}_{32} \mathrm{H}_{22} \mathrm{~N}_{4} \mathrm{OS}_{2}\right)$. Other peaks were in accordance with the proposed structure.

\subsection{Synthesis of poly(azomethine-ether)s}

A new homologous series of thermotropic liquid crystalline poly(azomethine-ether)s based on thiazole moiety $\mathbf{X I I}_{\mathbf{a}-\mathbf{e}} ; \mathbf{X I I I}_{\mathbf{a}-\mathbf{e}}$ were synthesized in high yields by solution polycondensation of bis(2aminothiazole) monomer $\mathbf{X}$ with two series of diformyl- $\alpha, \omega$-diphenoxyalkanes I-VIII This method was used for the preparation of conjugated polyazomethine arylidene polymers [18] and liquid crystalline poly (azomethine-ethert)s [19] as published in our previous work. The expected structures of the resulting poly(azomethine - ether)s $\mathbf{X I I}_{\mathbf{a}-\mathbf{e}}$ and XIII $_{\mathbf{a}-\mathbf{e}}$ were confirmed by elemental and spectral analyses. Results for the properties of the polymers

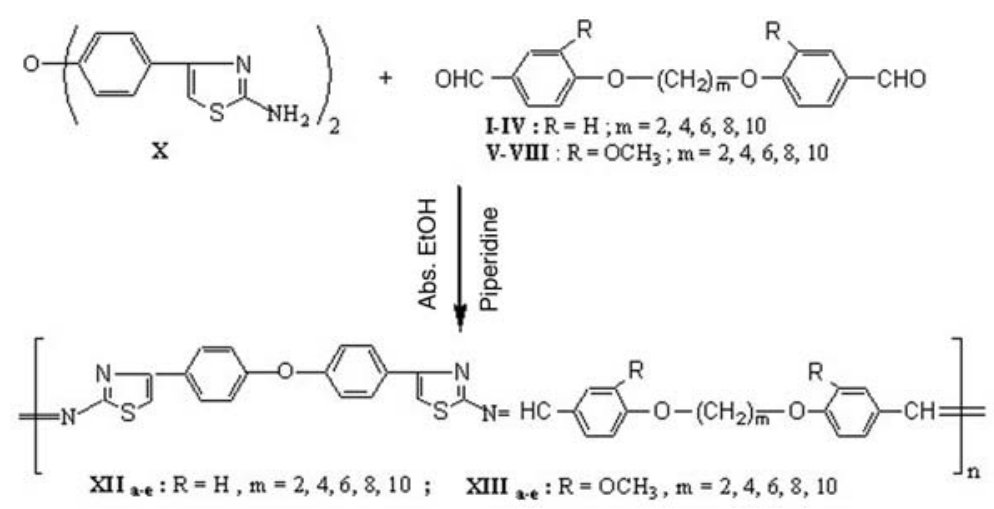

Figure 3. Synthesis of poly(azomethine-ether)s $\mathbf{X I I}_{\mathbf{a}-\mathbf{e}} ; \mathbf{X I I I}_{\mathbf{a}-\mathbf{e}}$ 
are listed in Table 1. The direct polycondensation easily affords high to moderate molecular mass polymers in quantitative yields. The monomers used and the polymers are depicted in Figure 3.

As mentioned in our previous work [18], the first successful synthesis of high molecular mass, wholly aromatic polyazomethines by the solution polycondensation technique, was that reported by Suematsu et al. [3]. This was followed by the work of Saegura et al. [20] who synthesized a series of polyazomethines containing heterocyclic moieties. Both groups used m-cresol as a solvent. Li and Chang [11] prepared a series of poly(azomethioneether)s in a mixture of m-cresol and o-chlorophenol at room temperature. In this work, m-cresol and ochlorophenol were not the solvents of choice, not only because it was difficult to remove water during the polymerization, but also because the heterogeneity of the reaction medium might have resulted in the formation of the low molecular mass polymers. Experimentation led us to believe that ethanol was a better solvent fore this purpose, because the poly(azomethine-ether)s with inherent viscosities up to $0.71 \mathrm{dl} / \mathrm{g}$ were readily obtained in high yield after a few minutes. The polycondensation results are summarized in Table 1. It should be noted that the analyses of the polymers deviated bym 1.2 to $1.5 \%$ from the theoretical values. However, it is not uncommon for the polymers to trap solvent molecules within the polymer matrix, especially polymers of high molecular weight [21]. Spectral data support the structural assignment for the resulting poly(azomethine-ether)s and the IR data from $\mathrm{KBr}$ disks for all the polymers showed characteristic absorption due to $\mathrm{CH}$ stretching of $\mathrm{CH}_{2}$ groups ( aliphatic spacers) at $2940-2860 \mathrm{~cm}^{-1}$,
$\mathrm{CH}=\mathrm{N}$ (azomethine) groups at $1620-1595 \mathrm{~cm}^{-1}$; phenylene rings at $1590-1510 \mathrm{~cm}^{-1}$ and $\mathrm{C}-\mathrm{O}-\mathrm{C}$ bonds (ether linkage) at $1240-1270 \mathrm{~cm}^{-1}$.

\subsection{Polymer characterization}

\subsubsection{Solubility}

The solubility characteristics of the poly(azomethie-ether)s $\mathbf{X I I}_{\mathbf{a}-\mathbf{e}}$ and $\mathbf{X I I I}_{\mathbf{a}-\mathbf{e}}$ were tested using various solvents including DMF (dimethylformamide), DMSO (dimethylsulfoxide), DMA (dimethylacetamide) THF (tetrahydrofuran), chloroform-acetone (1:1), methylene chloride, formic acid and conc. $\mathrm{H}_{2} \mathrm{SO}_{4}$. A $5 \%$ (w/v) solution was taken as a criterion for solubility. It can be clarified from Table 2 that all the poly (azomethine-ether)s are freely soluble in protonic acids like formic and $\mathrm{H}_{2} \mathrm{SO}_{4}$ acids. In common organic solvents and halogenated hydrocarbons all polymers are insoluble. In polar aprotic solvents, such as DMF, DMSO, DMA and THF, the majority of the polymers showed partial solubility (except, polymers $\mathbf{X I I I}_{\mathbf{b} \text {-e }}$ are dissolved easily). Comparing the solubility of polymers derived from 4,4'-diformyl- $\alpha, \omega$ diphenoxyalkanes (polymers $\mathbf{X I I}_{\mathbf{a}-\mathbf{e}}$ ) with those derived from 4,4'-diformyl-2,2' dimethoxy- $\alpha, \omega$ diphenoxyalkanes (polymers $\mathbf{X I I I}_{\mathbf{a}-\mathbf{e}}$ ), we found that the latter possesses better solubility than the former due to the presence of $\mathrm{OCH}_{3}$ groups with high steric effect as compared to those containing $\mathrm{H}$ atoms which make the solution easier. More particularly, presence of thiazole moiety in the polymer backbone leads to increasing chain packing distances and decreasing inter-chain interactions such as hydrogen bon ding so that making solution

Table 2. Solubility characteristics of poly(azomethine-ether)s $\mathbf{X I I}_{\mathbf{a}-\mathbf{e}}$ and $\mathbf{X I I I}_{\mathbf{a}-\mathbf{e}}$

\begin{tabular}{|c|c|c|c|c|c|c|c|c|}
\hline $\begin{array}{l}\text { Polymer } \\
\text { number }\end{array}$ & DMF & DMSO & DMA & THF & $\begin{array}{c}\text { Chloroform + Acetone } \\
(1: 1)\end{array}$ & $\mathrm{CH}_{2} \mathrm{Cl}_{2}$ & НСООН & Conc $\mathrm{H}_{2} \mathrm{SO}_{4}$ \\
\hline $\mathbf{X I I}_{\mathbf{a}}$ & + & + & + & + & - & - & ++ & ++ \\
\hline b & + & + & + & + & - & - & ++ & ++ \\
\hline c & + & + & + & + & - & - & ++ & ++ \\
\hline d & + & + & + & + & - & - & ++ & ++ \\
\hline e & + & + & + & + & + & + & ++ & ++ \\
\hline XIII $_{a}$ & + & ++ & ++ & + & - & + & ++ & ++ \\
\hline b & ++ & ++ & ++ & + & - & + & ++ & ++ \\
\hline c & ++ & ++ & ++ & ++ & - & + & ++ & ++ \\
\hline d & ++ & ++ & ++ & ++ & + & + & ++ & ++ \\
\hline e & ++ & ++ & ++ & ++ & + & + & ++ & ++ \\
\hline
\end{tabular}

++ Soluble at room temperature (RT)

+ : Partialy soluble at (RT)

-: Insoluble 
somewhat easier than other poly(azomethine)s [22].

\subsubsection{Inherent viscosity}

The inherent viscosities $\left(\eta_{i n h}\right)$ of all poly(azomethine-ether)s $\mathbf{X} \mathbf{I I}_{\mathbf{a}-\mathbf{e}}$ and $\mathbf{X I I I}_{\mathbf{a}-\mathbf{e}}$ were determined in concentrated sulphuric acid $(9 \mathrm{M})$ at $30^{\circ} \mathrm{C}$ with a Ubbelohde Suspended Level Viscometer. The inherent viscosity value is defined as Equation (1):

$\eta_{\text {inh }}=\frac{2.3}{C} \log \frac{\eta}{\eta_{0}}$

The solution concentration $C$ is $0.5 \mathrm{~g} / 100 \mathrm{ml}$, $\eta / \eta_{0}=$ relative viscosity (or viscosity ratio). The data are listed in Table 1. It can be clarified from this table that polymers $\mathbf{X I I}_{\mathbf{c}, \mathbf{e}}$ have high viscosity values $(1.21,1.19 \mathrm{dl} / \mathrm{g})$ and this may be attributed to high molecular weight of these two polymers. On the other hand, polymers $\mathbf{X I I}_{\mathbf{a}-\mathbf{c}}$ have low viscosities ( $0.61,0.49$ and $0.53 \mathrm{dl} / \mathrm{g}$ respectively), and this may be attributed to low molecular weight of these polymers. It should be noted also that the inherent viscosity of polymer $\mathbf{X I I}_{\mathbf{c}}$ (as a example) in concentrated sulphuric acid $(9 \mathrm{M})$ at $30^{\circ} \mathrm{C}$ decreased to around $2 \%$ during 4 days and then remained practically constant as shown in Figure 4, thus indicating the formation of a stable solution [23].

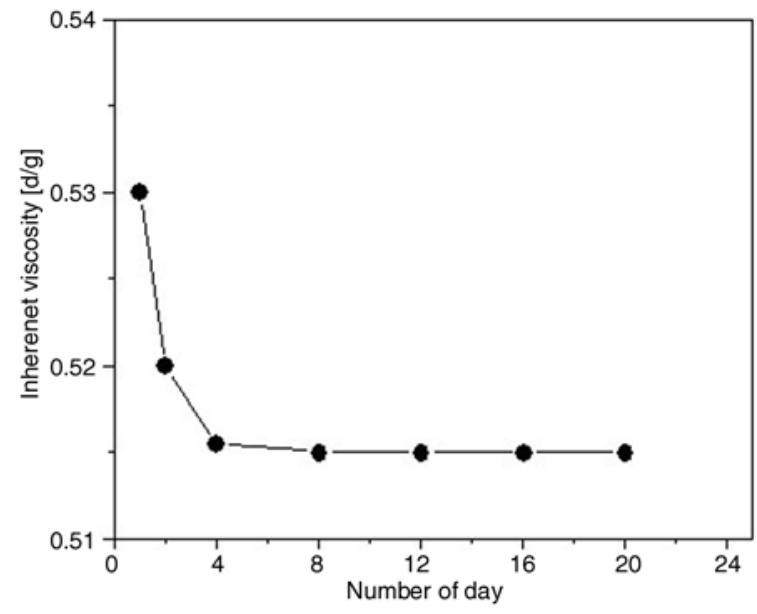

Figure 4. Stability of poly(azomethine - ether) $\mathbf{X I I}_{\mathbf{c}}$ in $\mathrm{H}_{2} \mathrm{SO}_{4}$ at $30^{\circ} \mathrm{C}$

\subsubsection{X-ray measurements}

The X-ray diffractograms of selected examples of the poly(azomethine-ether)s $\mathbf{X I I}_{\mathbf{b}, \mathbf{d}, \mathbf{e}}$ and $\mathbf{X I I I}_{\mathbf{b}, \mathbf{d}, \mathbf{e}}$ are shown in Figures 5, 6. The polymers show many reflection peaks that are ranging in crys- talline phase lying in region $2 \theta=5-60^{\circ}$. This indicates that there is a large class of structures that are intermediate in the ordered states between crystalline and amorphous phases (with pronounced long-range order) in the arrangement of their atoms

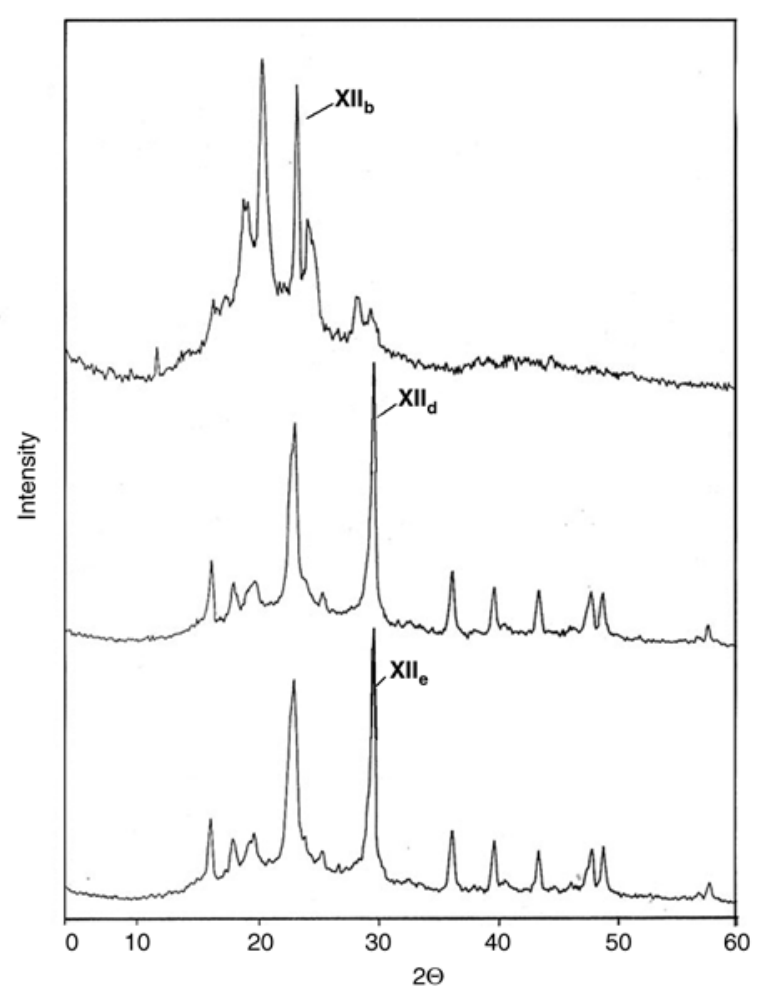

Figure 5. X-ray diffraction patterns of polymers $\mathbf{X I I}_{\mathbf{b}, \mathbf{d}, \mathbf{e}}$

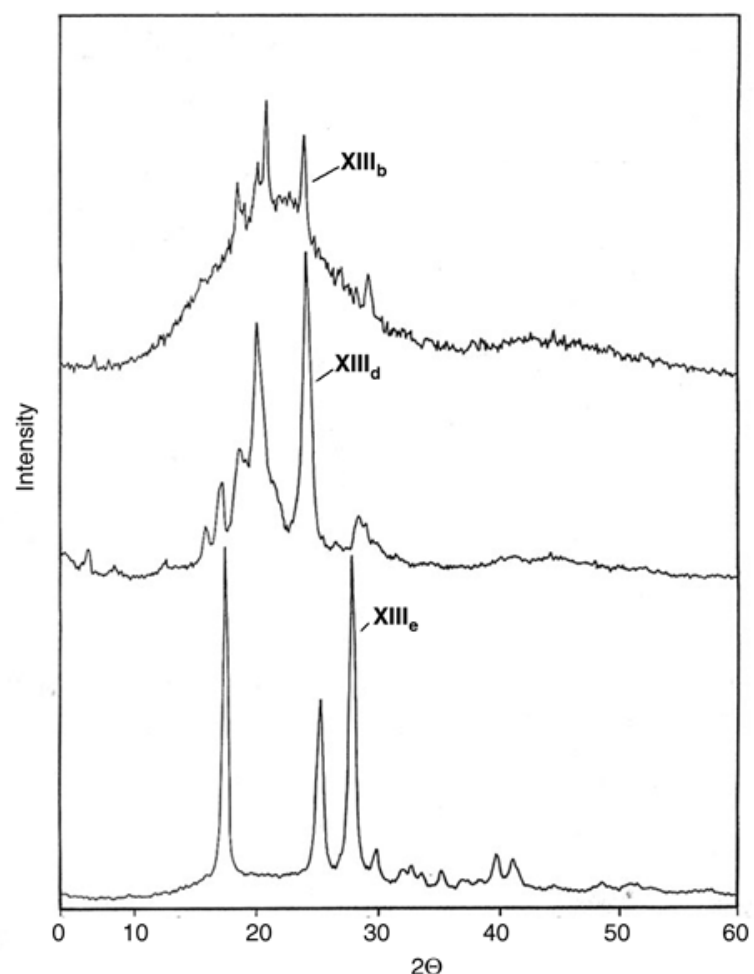

Figure 6. X-ray diffraction patterns of polymers $\mathbf{X I I I}_{\mathbf{b , d}, \mathbf{e}}$ 
and molecules. Moreover, the presence of $\mathrm{C}=\mathrm{N}$ as polar groups provides some order between two extent of crystallinity [24]. More particularly, the diffractograms of polymers $\mathbf{X I I}_{\mathbf{b}}, \mathbf{X I I I}_{\mathbf{b}}$ which contains short spacer $-\left(\mathrm{CH}_{2}\right)_{4}-$ shows few sharp reflection peaks (i.e. show semicrystalline characteristics). When the length of spacer increases, as in polymers $\mathbf{X I I}_{\mathbf{d}, \mathbf{e}}, \mathbf{X I I I}_{\mathbf{d}, \mathbf{e}}$ which contain eight or ten methylene groups $-\left(\mathrm{CH}_{2}\right)_{8}-$ or $-\left(\mathrm{CH}_{2}\right)_{10}$, the reflection sharpness increased and the polymer became crystalline. This is explained by the fact that increasing the number of methylene groups in the spacers results in increasing polymer chain flexibility [25], and hence increases crystallinity.

In addition, it was found that the absence of the bulky methoxy substituent in polymers $\mathbf{X I I}_{\mathbf{b}, \mathbf{d}, \mathbf{e}}$ and the presence of a hydrogen atom instead showed a tendency to higher crystallinity than in polymers $\mathbf{X I I I}_{\mathbf{b}, \mathbf{d}, \mathbf{e}}$ which contain methoxy substituent, where the presence of methoxy group as substituent in the phenyl ring caused some hindrance between the repeating units and forced it to unsymmetrical orientation in the polymer chains and reduced the closely packed structure i.e. crystallinity [26].

\subsubsection{Morphological features}

The morphology of the synthesized polymers was examined by scanning electron microscopy (SEM). The samples were prepared by putting a smooth part of polymer powder on a copper holder and subsequently coating it with gold palladium alloy. SEM images were taken on a penta Z Z-50 P Camera with Ilford film at an accelerating voltage of $15 \mathrm{kV}$ using a low-dose technique [27]. The study of selected polymers showed that the surface of polymer $\mathbf{X I I}_{\mathbf{a}}$ (Figure 7a, magnification $X=$ 1000) consisted of porous particles, with higher magnification showed cavity shape (Figure $7 \mathrm{~b}, X=$ 2000) while magnification of $X=3500$ (Figure 7c) showed more porous particles with globular grains.
However, the surface of polymer XIII (magnifica- $_{\text {- }}$ tion $X=1500)$ showed coral-like particles, with higher magnifications $(X=3500)$ showed spongy shape.

\subsection{Thermotropic liquid crystal properties of poly(azomethine-ether)s XII $\mathrm{X}_{\mathrm{a}-\mathrm{e}}$ and $\mathrm{XIII}_{\mathrm{a}-\mathrm{e}}$}

The thermal properties of the poly(azomethineether)s $\mathbf{X I I}_{\mathbf{a}-\mathbf{e}}$ and $\mathbf{X I I I}_{\mathbf{a}-\mathbf{e}}$ were characterized by DSC, TGA and by optical polarized microscope (OPM) with heating stage. The poly(azomethineether)s $\mathbf{X I I}_{\mathbf{a}-\mathbf{e}}$ and $\mathbf{X I I I}_{\mathbf{a}-\mathbf{e}}$ exhibit threadedschlieren texture of nematic and good spheroid texture during polarized microscope observation. The phase transition temperatures of the polymers are shown in Table 3. The microscopic observations by OPM allowed detection of the beginning of the melting process and the subsequent transition to the fully isotropic liquid, while the DSC measurements give the temperatures determined at the endothermal maxima [28]. The isotropization temperatures of these polymers was observed by using an optical polarizing microscope equipped with a heating stage in the temperature range of 163$280^{\circ} \mathrm{C}$ for the polymers $\mathbf{X I I}_{\mathbf{a}-\mathbf{e}}$ and $\mathbf{X I I I}_{\mathbf{c}-\mathbf{e}}$.

\subsubsection{DSC analyses}

In DSC studies, most of the polymers revealed multiple or more endothermic peaks on DSC thermograms, probably due to polymorphism [29]. In some cases, the peaks in DSC are broad, especially in polymers $\mathbf{X I I}_{\mathbf{a}, \mathbf{b}, \mathbf{c}}$ and $\mathbf{X I I I} \mathbf{I}_{\mathbf{c}}$, exhibiting thermal decomposition. For this reason, isotropization temperatures of the polymes were identified by observing the textures of the melts on a cross-polarizing microscope. All the poly(azomethine-ether)s were characterized by DSC (except $\mathbf{X I I}_{\mathbf{e}}$ and $\mathbf{X} \mathbf{I I I}_{\mathbf{a}, \mathbf{b}}$ ) and conducted at a heating and cooling rate $10^{\circ} \mathrm{C} \mathrm{min}^{-1}$. The heating traces of the polymers dis-
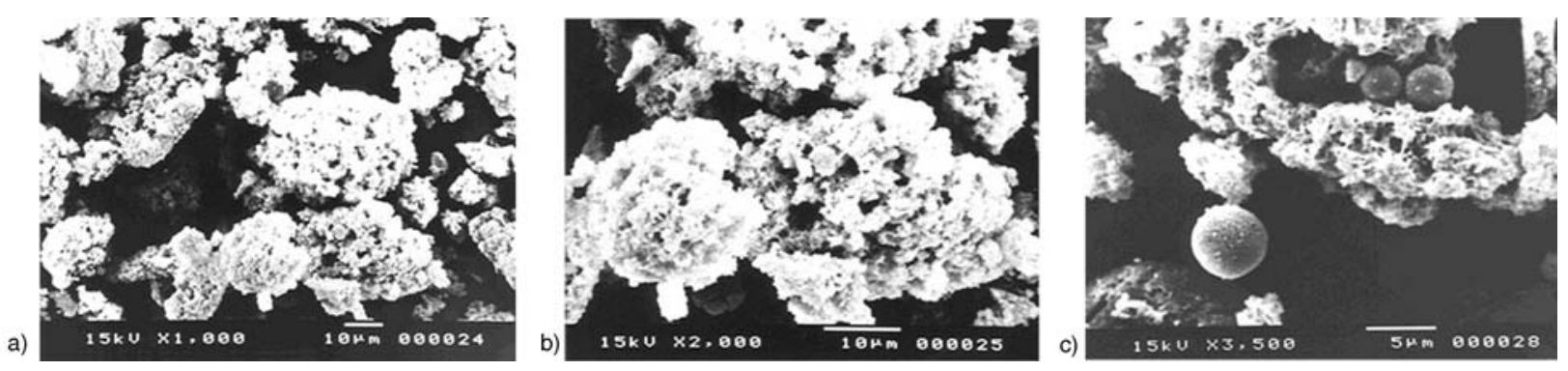

Figure 7. SEM images of polymer $\mathbf{X I I}_{\mathbf{a}}$ surface at different magnifications, a) $X=1000$; b) $X=2000$ and c) $X=3500$ 
Table 3. Transition behavior of poly(azomethine -ether)s $\mathbf{X I I}_{\mathbf{a}-\mathbf{e}}$ and $\mathbf{X I I I}_{\mathbf{a}-\mathbf{e}}$

\begin{tabular}{|c|c|c|c|c|c|c|c|c|c|}
\hline \multirow{2}{*}{$\begin{array}{l}\text { Polymer } \\
\text { number }\end{array}$} & \multirow[t]{2}{*}{$\mathbf{m}$} & \multirow[t]{2}{*}{$\mathbf{x}$} & \multirow{2}{*}{$\begin{array}{c}\text { Stirred } \\
\text { opalescence }\end{array}$} & \multicolumn{3}{|c|}{$\begin{array}{l}\text { Phase transition temperatures } \\
{\left[{ }^{\circ} \mathbf{C} \text {, microscope }\right]^{*}}\end{array}$} & \multicolumn{3}{|c|}{$\begin{array}{l}\text { Phase transition temperatures } \\
{\left[{ }^{\circ} \mathbf{C}, \text { DSC }\right]}\end{array}$} \\
\hline & & & & $\mathbf{T}_{\mathrm{m}}$ & $\mathbf{T}_{\mathbf{i}}$ & $\Delta \mathrm{T}$ & $\mathbf{T}_{\mathrm{m}}$ & $\mathbf{T}_{\mathbf{i}}$ & $\Delta \mathbf{T}$ \\
\hline $\mathbf{X I I}_{\mathbf{a}}$ & 2 & $\mathrm{H}$ & Strong & 227 & 280 & 53 & 224 & 288 & 64 \\
\hline b & 4 & $\mathrm{H}$ & Strong & 219 & 270 & 51 & 213 & 280 & 67 \\
\hline c & 6 & $\mathrm{H}$ & Strong & 179 & 257 & 78 & 180 & 268 & 88 \\
\hline d & 8 & $\mathrm{H}$ & Strong & 172 & 216 & 30 & 178 & 228 & 50 \\
\hline e & 10 & $\mathrm{H}$ & Strong & 153 & 166 & 13 & - & - & - \\
\hline XIII $_{\mathbf{a}}$ & 2 & $\mathrm{OCH}_{3}$ & None & - & - & - & - & - & - \\
\hline b & 4 & $\mathrm{OCH}_{3}$ & None & - & - & - & - & - & - \\
\hline c & 6 & $\mathrm{OCH}_{3}$ & Strong & 175 & 195 & 20 & 184 & 215 & 31 \\
\hline d & 8 & $\mathrm{OCH}_{3}$ & Strong & 169 & 182 & 13 & 175 & 204 & 29 \\
\hline e & 10 & $\mathrm{OCH}_{3}$ & Strong & 147 & 163 & 16 & 166 & 188 & 22 \\
\hline
\end{tabular}

${ }^{*}$ Measured by a polarizing microscope equipped with a heating stage

play a glass-transition $\left(T_{g}\right)$, which is weak in the case of polymer $\mathbf{X I I}_{\mathbf{c}}$ shows the DSC profiles of the melting process of sample $\mathbf{X I I}_{\mathbf{c}}$ that revealed multiple endotherms at $117^{\circ} \mathrm{C}\left(T_{g}\right), 180^{\circ} \mathrm{C}\left(T_{m}\right), 268^{\circ} \mathrm{C}$ $\left(T_{i}\right)$ and $371^{\circ} \mathrm{C}$, probably also indicating decomposition. When the sample was cooled after preheating to $440^{\circ} \mathrm{C}$, there were no endothermal or exothermal peaks. Figure 8 shows the DSC profiles of the melting process of sample $\mathbf{X I I}_{\mathbf{d}}$ that revealed multiple endotherms at $150^{\circ} \mathrm{C}\left(T_{g}\right), 178^{\circ} \mathrm{C}\left(T_{m}\right)$, $228^{\circ} \mathrm{C}\left(T_{i}\right)$ and $349^{\circ} \mathrm{C}$, also probably with decomposition. When the sample was cooled after preheating to $460^{\circ} \mathrm{C}$, there were no endothermal or exothermal peaks. This effect might be due to solid-to-solid $\left(T_{s s}\right)$, solid-to-mesophse $\left(T_{m}\right)$ and mesophase-to-solid $\left(T_{i}\right)$ [30] transitions which are observed by an optical microscope.

It should noted that, the phase transition temperature for polymers $\mathbf{X I I}_{\mathbf{c}}$ and $\mathbf{X I I}_{\mathbf{d}}$ respectively (see Figure 3), are very close to the temperature of the phase transitions observed by microscopy. The little difference between temperatures (not more than

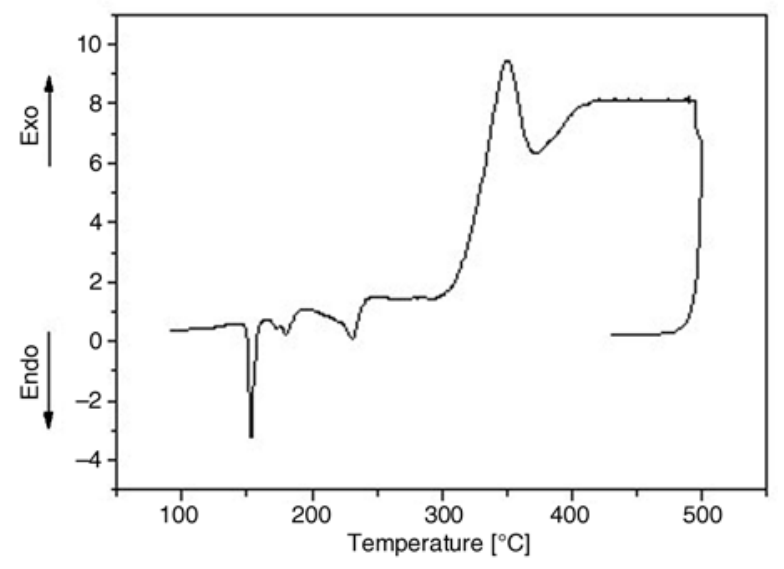

Figure 8. The DSC curve of polymer $\mathbf{X I I}_{\mathbf{d}}$ $12^{\circ} \mathrm{C}$ ) may be attributed to the observing of the temperatures during the raising in the microscopy $[2,31]$. The effect of spacer length on the thermal properties of poly(azomethine-ether)s $\mathbf{X I I}_{\mathbf{a}-\mathbf{e}}$ and $\mathbf{X I I I}_{\mathbf{a}-\mathbf{e}}$ is shown in Table 3; both melting point and isotropization temperature decreased as the length of the flexible aliphatic spacer in the polymer chain increased. The effect of substituents on the thermal properties of polymers $\mathbf{X I I}_{\mathbf{a}-\mathrm{e}}$ and $\mathbf{X I I I}_{\mathrm{a} \text {-e }}$ is also shown in Table 3 ; both the melting point and isotropization temperature decreased by the introduction of methoxy groups into the polymer main chain [32]. Similar observations were reported in previous work [33]. It is known that substituents can reduce the coplanarity of adjacent mesogenic groups and increase the diameter or decrease the axial ratio of the mesogenic units [34]. Thus, the unsubstituted para-linked poly(azomethine-ether)s is infusible below its decomposition temperature. But fusibility is achieved by the introduction of methoxy group into the mesogenic moiety, which lowers the transition temperatures, but of course; also decreases the orientational interactions thereby decreasing the mesophase stability [11].

\subsubsection{TGA measurements}

The thermal behavior of the poly(azomethine-ether)s $\mathbf{X I I}_{\mathbf{a} \text {-e }}$ and $\mathbf{X I I I}_{\mathbf{a} \text {-e }}$ was evaluated by TGA and DTG in air at a heating rate of $10^{\circ} \mathrm{C} \mathrm{min}{ }^{-1}$. TGA curves show a small weight loss in the range $2-4 \%$ starting at $160^{\circ} \mathrm{C}$ until $200^{\circ} \mathrm{C}$ which may be attributed to loss of observed moisture and entrapped solvents. The thermographs of selected examples from these polymers are given in Figures 9, 10 while Table 4 gives the temperatures for various percentages 


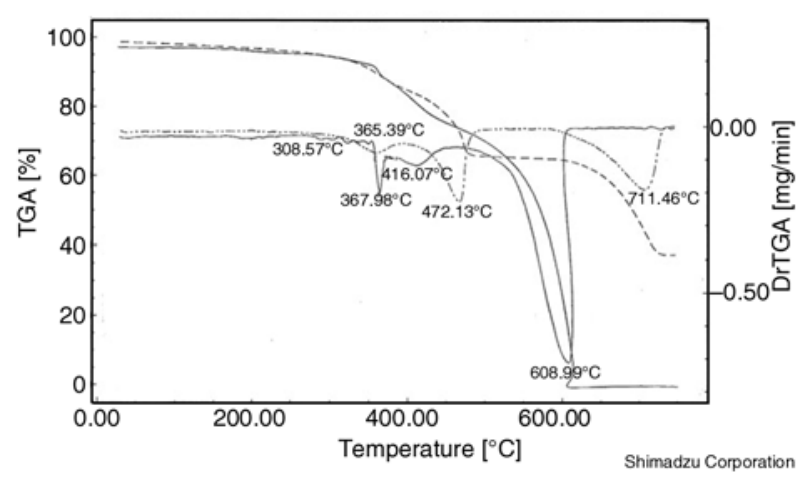

Figure 9. The TGA and DTG traces of polymers $\mathbf{X I I}_{\mathbf{c}}$ and XII $_{\mathbf{d}}$ in air at a heating rate of $10^{\circ} \mathrm{C} / \mathrm{min}$

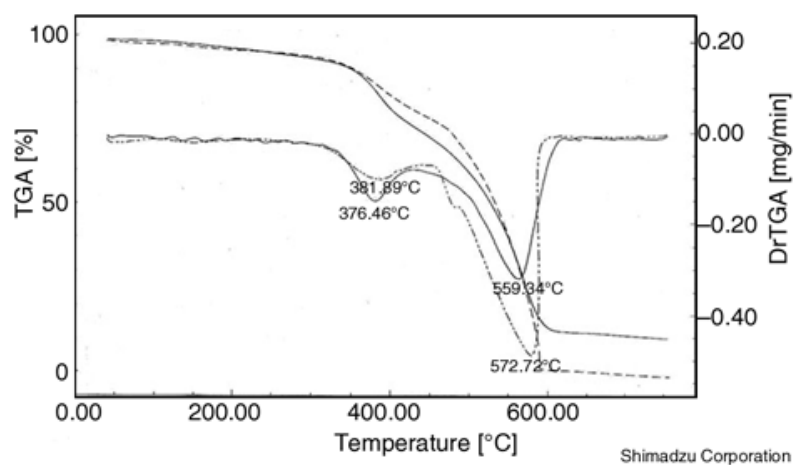

Figure 10. The TGA and DTG traces of polymers $\mathbf{X I I I}_{\mathbf{c}}$ and $\mathbf{X I I I}_{\mathbf{d}}$ in air at a heating rate of $10^{\circ} \mathrm{C} / \mathrm{min}$

Table 4. Thermal properties of poly(azomethin-ether)s $\mathbf{X I I}_{b-\mathrm{e}}$ and $\mathbf{X I I I}_{\mathbf{c}-\mathrm{e}}$

\begin{tabular}{|r|c|c|c|c|c|}
\hline \multirow{2}{*}{$\begin{array}{c}\text { Polymer } \\
\text { number }\end{array}$} & \multicolumn{4}{|c|}{ Temperature $\left[{ }^{\circ} \mathbf{C}\right]$ for various \% decomposition* } \\
\cline { 2 - 6 } & $\mathbf{1 0}$ & $\mathbf{2 0}$ & $\mathbf{3 0}$ & $\mathbf{4 0}$ & $\mathbf{5 0}$ \\
\hline XII $_{\mathbf{b}}$ & 378 & 409 & 460 & 487 & 513 \\
\hline $\mathbf{c}$ & 378 & 436 & 516 & 553 & 582 \\
\hline $\mathbf{d}$ & 368 & 450 & 478 & 656 & 690 \\
\hline e & 387 & 427 & 509 & 541 & 562 \\
\hline XIII $_{\mathbf{c}}$ & 360 & 400 & 454 & 497 & 530 \\
\hline d & 363 & 420 & 477 & 508 & 536 \\
\hline e & 370 & 424 & 498 & 533 & 556 \\
\hline
\end{tabular}

*The values were determined by TGA at heating rate of $10^{\circ} \mathrm{C} / \mathrm{min}$

weight loss. The initial decomposition of these polymers (5\% loss) started at $312^{\circ} \mathrm{C}$ for series $\mathbf{X I I}_{\text {a-e }}$

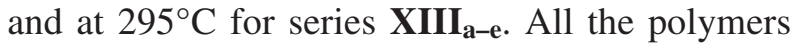
showed similar decomposition patterns in two steps except polymers $\mathbf{X I I}_{\mathbf{b}-\mathbf{d}}$ which occurs in three steps. The first step is slow and ranges between 249 and $443^{\circ} \mathrm{C}$; the second step is a fast degradation and ranges between 456 and $645^{\circ} \mathrm{C}$ the extended nature of the decomposition of these polymers is through pyrolytic oxidation $\mathrm{C}=\mathrm{N}$ and rupture of many bonds. The degradation becomes maximal at around $550^{\circ} \mathrm{C}$ and is nearly complete at around $720^{\circ} \mathrm{C}$. The temperature for $10 \%$ weight loss is considered to be the polymer decomposition temperature [25, 35] (PDT); it occurs in the range 360$387^{\circ} \mathrm{C}$ for all the polymers. In Figures 9, 10 mass loss is seen to be rapid between $\sim 340-392^{\circ} \mathrm{C}$ for polymer XII $_{\mathbf{c}}$ in the first region, between $~ 395$ $473^{\circ} \mathrm{C}$ in the second region and between $\sim 475$ $664^{\circ} \mathrm{C}$ in the third region. For polymer $\mathbf{X I I}_{\mathbf{d}}$, the mass loss was rapid between $\sim 259-396^{\circ} \mathrm{C}$ in the first region, between $\sim 400-530^{\circ} \mathrm{C}$ in the second region and between $\sim 535-720^{\circ} \mathrm{C}$ in the third region. For polymer $\mathbf{X I I I}_{\mathbf{c}}$, the mass loss was rapid between $\sim 279-410^{\circ} \mathrm{C}$ in the first region, between $\sim 413-709^{\circ} \mathrm{C}$ in the second region. For polymer XIII $_{d}$, the mass loss was rapid between $~ 268$ $409^{\circ} \mathrm{C}$ in the first region, between $\sim 415-607^{\circ} \mathrm{C}$ in the second region.

It should be noted that, the behavior of all polymers in the first region was nearly identical. The expected nature of decomposition of this type of polymer is a pyrolytic oxidation of $\mathrm{C}=\mathrm{N}$, scission of many bonds, in addition to the formation of char as an end product [15]. Polymers $\mathbf{X I I}_{\mathbf{a}-\mathbf{e}}$ containing no methoxy substituent in the main chain is somewhat higher in thermal stability than polymers $\mathbf{X I I I}_{\mathbf{a}-\mathrm{e}}$. All the synthesized polymers exhibit higher thermal stability than other similar poly(azomethine-ether)s, which may be attributed to the presence of thiazole moiety in the polymers main chain.

\subsubsection{Texture observation}

To support further the information gained by DSC on the thermotropic behavior of the synthesized polymers, qualitative observation of the textures between crossed polarizers was carried out for poly(azomethine-ether)s $\mathbf{X I I}_{\mathbf{a}-\mathbf{e}}$ and $\mathbf{X I I I}_{\mathbf{a}-\mathbf{e}}$. Optical microscopy showed that all the polymers melt yield viscous, birefringent liquid crystal phases except polymers $\mathbf{X I I I}_{\mathbf{a}, \mathbf{b}}$, which did not show any birefringence, so providing direct evidence for lack of mesomorphic behavior for these polymers. The temperatures correspond roughly with those observed by DSC; differences may be due to variations in heating rates. The character of the texture at a given temperature was fixed by quenching it in liquid nitrogen. Micrographs were then obtained on heating to room temperature (not shown). Observation of poly(azomethine-ether) $\mathbf{X I I}_{\mathbf{b}}$ under a polarizing microscope revealed that this polymer exhibited a threaded-schlieren texture of nematic 


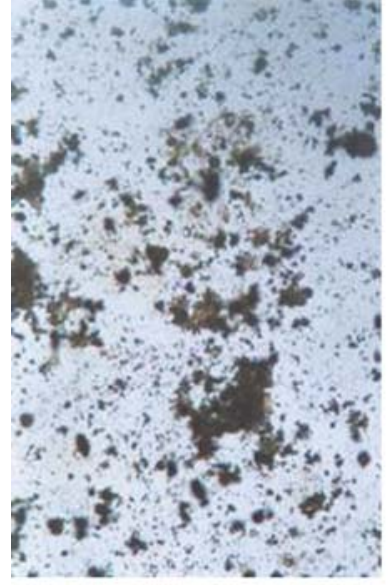

a)

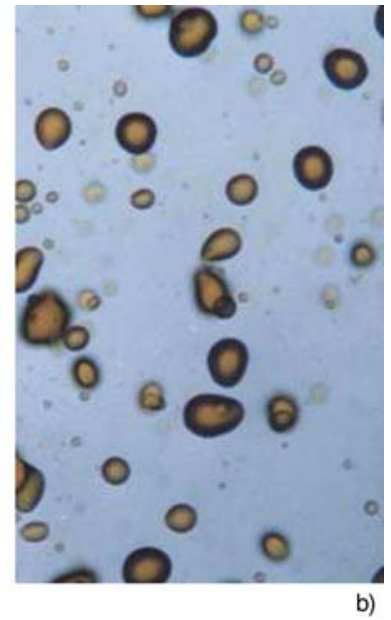

Figure 11. Photomicrographs of polymer $\mathbf{X I I}_{\mathbf{b}}$ in the heating cycle at (a) $219^{\circ} \mathrm{C}$, (b) $270^{\circ} \mathrm{C}$ (Magnification $X=200$ )

phase with a thick dark rim in Figure 11a (before melting), and the mesophase extend up to the isotropic at $270^{\circ} \mathrm{C}\left(T_{i}\right)$. After cooling to room temperature a highly spheroidal texture appeared (c.f. Figure 11b).Observation of poly(azomethine-ether) $\mathbf{X I I}_{\mathbf{c}}$ in the anisotropic melt displayed the typical schlieren textures as shown in (before melting), and at $257^{\circ} \mathrm{C}\left(T_{i}\right)$.

In addition to, observation of poly(azomethineether) XIII $_{\mathbf{d}}$ under a polarizing microscope revealed that this polymer exhibited a good spheroid structure with a thick dark rim (before melting), and the mesophase extends up to the isotropization temperature at $182^{\circ} \mathrm{C}\left(T_{i}\right)$. After cooling to room temperature a highly spheroidal texture appeared.

The textures observed were generally grey, although annealing samples for long periods led to the formation of well developed schlieren textures [36].

\section{Conclusions}

A novel series of thermally stable liquid crystalline poly(azomethine-ether)s containing thiazole moiety have been synthesized. A solution polycondensation technique at $\sim 80^{\circ} \mathrm{C}$ was used. The majority of the polymers are insoluble in common organic solvents and halogenated hydrocarbons. Most of them exhibited melt birefringence and stirred opalescence during polarized microscope observation.

Both $\left(T_{m}\right)$ and $\left(T_{i}\right)$ values increased as the length of the flexible aliphatic spacers increased and decreased with introduction of the methoxy group as a substituent in the polymers main chain.

\section{Acknowledgements}

It is pleasure to acknowledgement Dr. M. Abd El-Moniem at Geology Department, Faculty of Science, Assiut University for his assistance in the Optical properties measurements.

\section{References}

[1] Janneli P., Roviello A., Sirigu A.: Liquid crystal behavior of linear copolymers I. European Polymer Journal, 18, 745-751 (1982).

[2] Sek D.: Liquid crystalline properties of new poly (azomethine esters). European Polymer Journal, 20, 923-926 (1984).

[3] Suematsu K., Nakamurra K., Takeda J.: Synthesis of aromatic polyimines by the condensation of aromatic dialdehyde and diamine. Colloid and Polymer Science, 261, 493-501 (1983).

[4] Sek D.: Synthesis of polyazomethinesters and relationship between their structures and thermal stability. Polymer Journal, 14, 173-179 (1982).

[5] Roviello A., Sirigu A.: Mesophasic structures in polymers. A preliminary account on the mesophases of some poly-alkanoate of p,p'-dihydroxy- $\alpha, \alpha$ '-dimethyl benzalazin. Journal of Polymer Science: Polymer Letters Edition, 13, 455-463 (1975).

[6] Ober C. K., Jin J. I., Lenz R. W.: Liquid crystal polymer I. Springer-Verlag, Berlin (1984).

[7] Chapoy L. L: Recent advances in liquid crystalline polymers. Elsevier, London (1986).

[8] Morgan P. W., Kwolek S. L., Pletcher T. C.: Aromatic azomethine polymers and fibers. Macromolecules, 20, 729-739 (1987).

[9] Guillon D., Skoulion A.: Mesophases smectiques thermotropes de polybases de Schiff. Molecular Crystals and Liquid Crystals, 49, 119-123 (1978).

[10] Wojtkowski P. W.: Aromatic-aliphatic azomethine ether. Polymers and fibers. Macromolecules, 20, 740-749 (1987).

[11] Li C-H., Chang T-C.: Studies on thermotropic liquid crystalline polymers-part II. Synthesis and properties of poly(azomethine-ether). European Polymer Journal, 27, 35-39 (1991).

[12] Perrin D. D., Armarigo W. L. F., Perrin D. F.: Purification of laboratory chemicals. Pergamon, New York (1980).

[13] Liang A. L., Hsu K. Y., Li C. H., Chang T. C.: Studies on thermotropic liquid crystalline polymers: 4. Synthesis and properties of poly (ether ester amide)s. Polymer, 33, 2217-2221 (1992).

[14] Aly K. I.: Liquid crystalline polymers: 2. synthesis and thermotropic studies of poly (arylidene-ether)s containing cyclo pentanone moiety in the main chain. High Performance Polymers, 11, 437-452 (1999).

[15] Aly K.I.: Liquid crystalline polymers: 3. Synthesis and liquid crystal properties of thrmotropic poly(arylidene-ether)s and copolymers containing cycloalkanone moiety in the polymer backbone. Journal of 
Macromolecular Science, Part A: Pure and Applied Chemistry, 37, 93-115, (2000).

[16] Joule J. A., Smith G. G.: Heterocyclic chemistry. Blackvell Science, Oxford (2000).

[17] Patai S.: Chemistry of carbonyl group, Jonathan Grobe Books, Deep River (1966).

[18] Aly. K. I., Khalaf A. A.: New polymer syntheses IX. Synthesis and properties of new conducting polyazomethine polymers containing main chain cycloalkanone and pyridine moieties. Journal of applied polymer science, 77, 1218-1229 (2000).

[19] Aly K. I., Ahmed R. A.: Liquid crystalline polymers V. Thermotropic liquid crystalline poly(azomethineether)s containing cycloalkanone moiety in the polymer backbone. Liquid Crystals, 27, 451-458 (2000).

[20] Saegura Y., Koshikawa T., Nakamura S.: Synthesis and characterization of 1,3,4-oxadiazole-containing polyazomethines. Journal of Polymer Science: Polymer Chemistry, 30, 1369-1373 (1992).

[21] Andrew S. M., Bass R. G.: Polypyrazolinones from aromatic di(propynoic ester)s and aromatic dihydrazines. Journal of Polymer Science Part A: Polymer Chemistry, 27, 1225-1239 (1989).

[22] Hsiao S. H., Liou G. S.: A new class of aromatic poly(1,3,4-oxadiazole)s and poly (amide-1,3,4-oxadiazole)s containing (naphthalene dioxy)diphenylene groups. Polymer Journal, 34, 917-924 (2002).

[23] Patra S.; Lenka S., Nayak P. L.: Synthetic resins II. Preparation and characterization of resins prepared from aminoacetophenone. Journal of Applied Polymer Science, 32, 5071-5083 (1986).

[24] Mandelkern L: Crystallization of polymers. McGrawHill, New York (1964).

[25] Aly K. I.: New polymer syntheses VIII. Synthesis, characterization and morphology of new unsaturated copolyesters based on dibenzylidene-cycloalkanones. Polymer International, 47, 483-490 (1998).
[26] Aly K. I.: The synthesis and characteristics of some new polymeric quinone and diarylidene derivatives. Ph.D. Thesis, Assiut University, Egypt 1989.

[27] Tager A.: Physical Chemistry of Polymers. Mir, Moscow (1972).

[28] Aly K. I.: New polymer syntheses III. Synthesis and characterization of new unsaturated polycarbonates. High Performance Polymers, 6, 149-154 (1994).

[29] Roviello A., Sirigu A.: Poly[oxytetradecanedioyloxy1,4-phenylene-(2 methylvinylene)-1,4-phenylene]. A polymer showing monotropic mesomorphism. Die Makromolekulare Chemie, 180, 2543-2545 (2003).

[30] Sato M., Manabf Y., Sasaki T., Ohtomo Y., Komatsu F.: Synthesis and thermal properties of novel thermotropic aromatic - aliphatic homo- and copolyamides. European Polymer Journal, 27, 1391-1395 (1991).

[31] Sek D.: Synthesis and properties of new poly(azomethinesters). European Polymer Journal, 20, 805-809 (1984).

[32] Ozcayir Y., Blumstein A.: Diacetylenic liquid-crystalline polymers and copolymers I. Derivatives of diphenyldiacetylene. Journal of Polymer Science: Polymer Chemistry, 24, 1217-1225 (1986).

[33] Aly K. I., Hammam A. S.: Liquid crystalline polymers I. Main chain thermotropic poly (arylidene-ether)s containing cyclopentanone moiety linked with polymethylene spacers. European Polymer Journal, 36, 1933-1942 (2000).

[34] Ober C. K., Jin J. I., Lenz R. W.: Liquid Crystal Polymer Springer-Vertag Berlin (1984).

[35] Aly K. I., Abd-Alla A.: Arylidene polymers XX. Synthesis and characterization of some new photochromic heterocyclic arylidene polymers contaning 1,3,4-oxadiazole and 1,2,4- triazole moieties in the main chain. Polymer Journal, 24, 165-171 (1992).

[36] Demus D., L. Richter: Textures of liquid crystals. Verlag Chemie, Weinheim (1978). 